\title{
First record of a male of Kryptolebias hermaphroditus Costa, 2011 (Cyprinodontiformes: Cynolebiidae)
}

\author{
Waldir M. Berbel-Filho ${ }^{1,2}$, Helder M. V. Espírito-Santo ${ }^{3}$ and Sergio M. Q. Lima ${ }^{1}$
}

During an ichthyological survey in September 2015 at the Ceará-Mirim River estuary, Rio Grande do Norte State, northeastern Brazil, we collected a male of Kryptolebias hermaphroditus, a cynolebiid species that had been previously described as containing exclusively self-fertilizing hermaphrodites. This is the first record of a male in this species, over 140 years after the discovery of the mangrove rivulid species from Brazil. Our discovery reinforces the need for more studies in $K$. hermaphroditus, as well as the potential of this species as a model for evolutionary studies due to its unique mating system.

Durante uma amostragem ictiológica em setembro de 2015 no estuário do rio Ceará-Mirim, Estado do Rio Grande do Norte, Nordeste do Brasil, nós coletamos um macho de Kryptolebias hermaphroditus, uma espécie de rivulídeo que foi descrita como contendo apenas hermafroditas auto-fertilizantes. Este é o primeiro registro de um macho dessa espécie, mais de 140 anos depois da descoberta das espécies de rivulídeos de manguezais do Brasil. Nossa descoberta reforça a necessidade de mais estudos em $K$. hermaphroditus, assim como, o potencial desta espécie como um modelo para estudos evolutivos devido ao seu sistema reprodutivo único.

Keywords: Hermaphroditism, Mangrove killifish, Mid-Northeastern Caatinga ecoregion, Mixed-mating system, Sexual dimorphism.

\section{Introduction}

Although the overall taxonomy of Kryptolebias Costa, 2004 is confusing (Costa, 2006), the K. marmoratus species group is well supported by both molecular (Tartarenkov et al., 2009) and morphological data (Costa et al., 2010). The species comprising this group, K. marmoratus (Poey, 1880), K. ocellatus (Hensel, 1868) and K. hermaphroditus Costa, 2011, inhabit estuarine areas associated with mangroves, ranging from southeastern United States of America to southern Brazil (Costa, 2011). Besides this unusual brackish habitat, these species are also unique among aplocheiloid killifishes due to the absence of females, which are replaced by hermaphrodites (Costa et al., 2010).

Indeed, self-fertilizing hermaphroditism is the dominant mode of reproduction in Kryptolebias marmoratus distributed from Florida to Venezuela (Tatarenkov et al., 2011) and K. hermaphroditus occurring in the Atlantic Forest mangroves of Brazil (Lira et al., 2015). This clade represents the only occurrence of self-fertilizing hermaphroditism among vertebrates (Tartarenkov et al.,
2009; Costa et al., 2010). Because of its reproductive mixedmated system, K. marmoratus has been a popular model species for embryological, physiological, behavioral and genetic studies (Avise \& Tatarenkov, 2015). While males are rare in $K$. marmoratus, they are considered to be absent in K. hermaphroditus (Costa, 2011; Tatarenkov et al., 2011), despite this species having been known at least since 1868 (previously known as $K$. ocellatus) and numerous museum and unpreserved specimens have been examined (Costa, 2011). Due to the absence of males in fish collections, and following a re-examination of the holotype of $K$. ocellatus, the monomorphic hermaphrodite species from Brazil was described as K. hermaphroditus (Costa, 2011).

Hermaphrodites of both species (K. marmoratus and $K$. hermaphroditus) typically have a black ocellus on the caudal peduncle and a dark-grey body side (Soto \& Noakes, 1994; Costa, 2011). In K. marmoratus, males exhibit a bright orange coloration on the body flank and fins, an absent or poorly-defined ocellus on the caudal peduncle, and black margins on the caudal fins (Davis et al., 1990; Soto \& Noakes, 1994; Costa, 2011).

\footnotetext{
${ }^{1}$ Laboratório de Ictiologia Sistemática e Evolutiva, Departamento de Botânica e Zoologia, Universidade Federal do Rio Grande do Norte, Av. Senador Salgado Filho 3000, 56078-970 Natal, RN, Brazil. (SMQL) smaialima@gmail.com, (WMBF) waldirmbf@hotmail.com (corresponding author) ${ }^{2}$ Department of BioSciences, College of Science, Swansea University, SA2 8PP, Swansea, Wales, United Kingdom ${ }^{3}$ Post-Doctoral Program, Instituto Nacional de Pesquisas da Amazônia, Av. André Araújo, 2936, Petrópolis, 69067-375 Manaus, AM, Brazil. espiritosantohm@gmail.com
} 
In a recent collection in the Ceará-Mirim River estuary, we found a Kryptolebias hermaphroditus individual with a male phenotype. Considering that this species has been described as being completely composed of hermaphrodites, the main objective of the present study is to record and describe the first occurrence of a male K. hermaphroditus.

\section{Material and Methods}

In September 2015, during a nocturnal exploratory fieldwork being conducted with the objective of designing an ecological study on Kryptolebias hermaphroditus at the

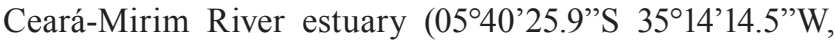
see Lira et al., 2015 for a map and detailed description of the area), we observed a bright orange individual of Kryptolebias (Fig. 1). This specimen together with specimens exhibiting a more typical hermaphroditic appearance, were captured by hand and with the help of a hand sieve $(50 \times 60 \mathrm{~cm}, 1$ $\mathrm{mm}$ mesh), under permit \#30532-1/2011 issued by ICMBio/ SISBIO. The fishes were euthanized using clove oil, fixed in formalin solution, transferred to an $70 \%$ alcohol solution and then deposited in the ichthyological collection of Universidade Federal do Rio Grande do Norte (UFRN 3774, 8 ex.). Some other individuals, as well as a small fin-clip (TIUFRN 3481; tissue collection of UFRN), were directly stored in $96 \%$ ethanol for molecular analysis.

Measurements and counts for the orange individual follow Costa (1995). Kryptolebias species identification was carried out using the key proposed by Costa (2009), and later confirmed using Costa (2011). To identify male traits, we used the information described for the closely related species K. marmoratus (Davis et al., 1990; Soto \& Noakes, 1994; Costa, 2011).

\section{Results}

All specimens were identified as Kryptolebias hermaphroditus on the basis of having 1-4 teeth in the vomer and a color pattern with silvery or pale golden spots on the dorsal part of the flank. The male individual had bright orange coloration on the body flank and fins (mainly dorsal, anal and caudal), and black margins on the anal and caudal fins (Fig. 1), as in males of $K$. marmoratus.

Comparing male and hermaphroditic phenotypes of the captured specimens, both have a dark ocellus on the caudal peduncle; however, the ocellus is faint on the male specimen. The hermaphrodites consistently exhibit a brown or grey flank coloration, as well as hyaline unpaired fins with pale grey dots on the basal portion, whereas the male individual exhibits unpaired fins with orange coloration (Fig. 2).

Description. Morphometric data of male $(30.1 \mathrm{~mm} \mathrm{SL})$ in Table 1. Urogenital papilla cylindrical in male, pocketlike shape in hermaphrodites (Fig. 3). Dorsal fin rounded. Anal fin sub-trapezoidal, distal margin slightly damaged; anal-fin rays 4 and 5 longer than other anal-fin rays. Caudal fin oval, deeper than long. Pectoral fin short and rounded. Pelvic fin elliptical. Pelvic-fin bases medially separated by short interspace. Dorsal-fin origin at vertical between 9th and 10th anal-fin rays. Dorsal-fin rays 8; anal-fin rays 11; caudal-fin rays 30; pectoral-fin rays 13; pelvic-fin rays 6 .

Scales small, cycloid. Frontal squamation E-patterned. Longitudinal series of scales 47; transverse series of scales 13; scale rows around caudal peduncle 25 . Contact organs absent.

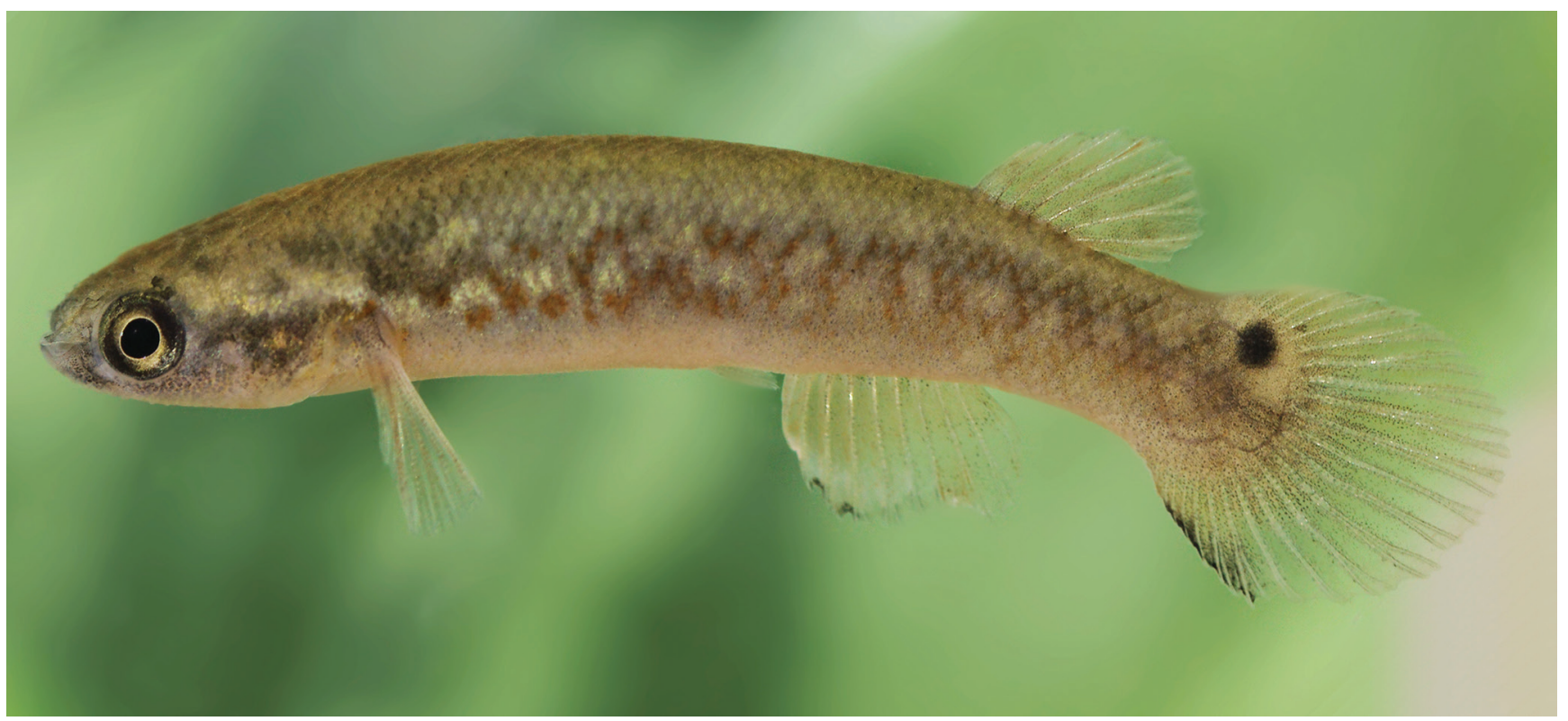

Fig. 1. Kryptolebias hermaphroditus, male, UFRN 3774, 30.1 mm SL (three days after sampling); Ceará-Mirim River estuary, Extremoz, Rio Grande do Norte, Brazil. 


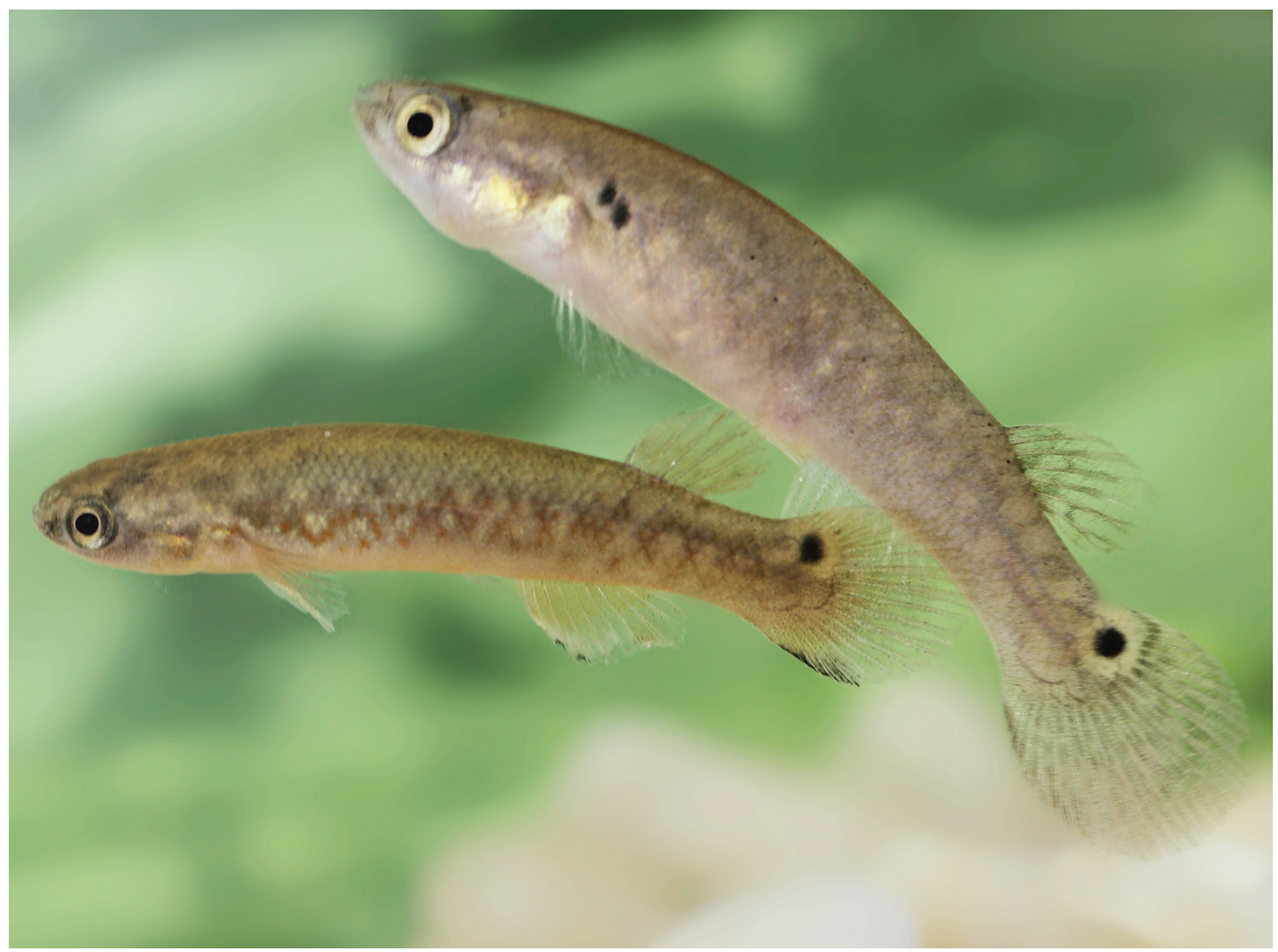

Fig. 2. Kryptolebias hermaphroditus, male (below) $30.1 \mathrm{~mm}$ SL, hermaphrodite (above) $35.5 \mathrm{~mm}$ SL, UFRN 3774, CearáMirim River estuary, Extremoz, Rio Grande do Norte, Brazil.

Table 1. Morphometric data of the Kryptolebias hermaphroditus, male (UFRN 3774).

\begin{tabular}{lc}
\hline Standard length (mm) & 30.16 \\
$\quad$ Percents of standard length & 17.11 \\
Body depth & 13.23 \\
Caudal-peduncle depth & 73.18 \\
Predorsal length & 62.10 \\
Prepelvic length & 12.33 \\
Length of dorsal-fin base & 15.78 \\
Length of anal-fin base & 25.86 \\
Caudal-fin length & 17.90 \\
Pectoral-fin length & 6.63 \\
Pelvic-fin length & 25.10 \\
Head length & \\
$\quad$ Percents of head length & 59.31 \\
Head depth & 71.07 \\
Head width & 29.33 \\
Snout length & 23.51 \\
Lower-jaw length & 26.55 \\
Eye diameter
\end{tabular}

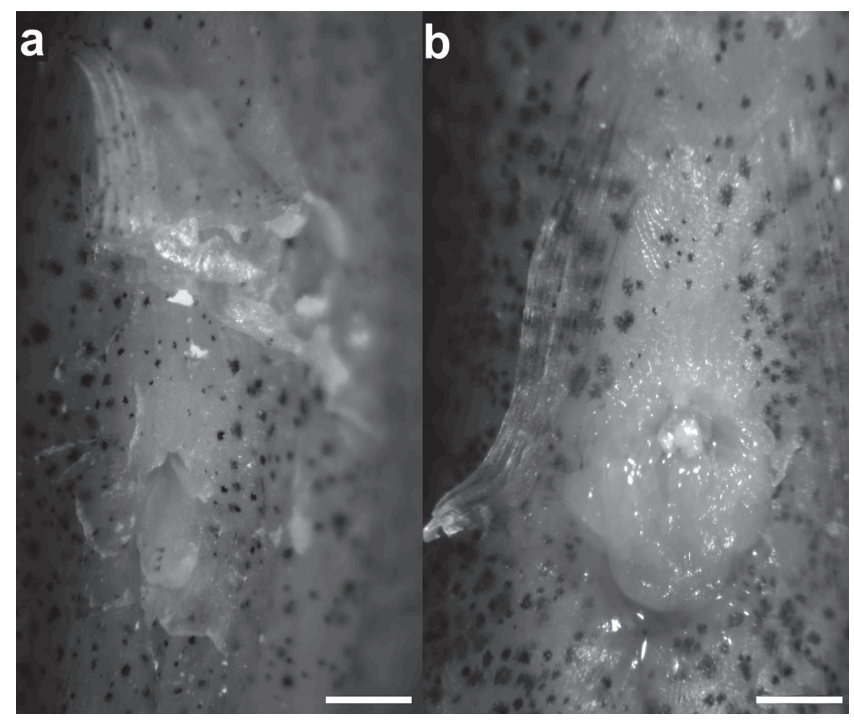

Fig. 3. Urogenital papillae of Kryptolebias hermaphroditus in ventral view; UFRN 3374: a, cylindrical shape in male, $30.1 \mathrm{~mm} \mathrm{SL}$; b, pocket shape in hermaphrodite, $35.5 \mathrm{~mm}$ SL. Scale bars $=1 \mathrm{~mm}$. 
Coloration. Flank dark grey on anterior and dorsal portion of head, from greyish to orange on posterior and ventral portions. Side of the body intensely pigmented with faint dark grey stripe between postorbital region and caudal-fin base, and small irregular somewhat zigzag pattern composed of small orange spots more concentrated on anterior half of body side. Inconspicuous dark grey humeral blotch; rounded dark spot with faint yellowish grey margin on dorsal end of caudal peduncle. Side of head light brown on dorsal portion, pale golden with dark grey dots ventrally. Jaws grey. Iris brown, with narrow pale yellow margin around pupil. Dorsal, anal and caudal fins hyaline with dark orangish-brown on basal and medial portions of fins; black stripe on distal anterior margin of anal and lower portion of caudal fin. Pectoral and pelvic fins hyaline. Bright orange coloration faded a little after sampling, probably due to stress and nonnatural conditions (Figs. 1-2).

Ecological notes. The sampling locality had clear water and the fishes could be observed using flashlights. The Kryptolebias hermaphroditus male was captured in an ephemeral pool at higher elevations among the estuary's mangroves. This pool had at least four fiddler crabs (Uca maracoani Latreille, 1802) burrow openings and, prior to our approach, the male fish was resting on the water's surface near one of these burrows. During our sampling attempts, the fish repeatedly hid and re-appeared among the crab burrows, appearing periodically in different openings until it was caught. Time between reappearances was about one minute.

Large (23.2-35.5 mm SL) hermaphrodites were also collected in the same area as the male, in shallow pools formed in the edge of the mangroves; in the inner and deeper pools, Poecilia vivipara Bloch \& Schneider, 1801 was the dominant species. Guavina guavina (Valenciennes, 1837), potential predator of Kryptolebias hermaphroditus, were also active during the night and observed entering the same large crab burrows. Salinity in these pools, previously recorded in January 2015 at the same site, was 34-36 ppm during the low tide.

\section{Discussion}

Over the 140 years, since the description of Kryptolebias ocellatus (as was long called hermaphroditic species who was later described as $K$. hermaphroditus) from a mangrove in Rio the Janeiro, no males of this hermaphroditic species from the Brazilian coast have ever been found (Costa, 2011). However, potential miswritten on previous literature (Costa, 2006; Lira et al., 2015) needs to be clarified for a better understanding of the issue. Both studies used the subjective term "rare" while discussing the existence of males in K. hermaphroditus. Costa (2006) had already mentioned two reports of potential $K$. hermaphroditus males based on pictures and brief descriptions of live specimens with light grey and dark orange spots on the flanks, grey humeral and caudal peduncle spots and dark grey to black distal zones of unpaired fins. However, this author recognized that this material was not preserved for study in any scientific collection and needed posterior confirmation. Posteriorly, Costa (2011) described K. hermaphroditus as only composed by hermaphrodites, discarding the relevance of the two previous unconfirmed reports. In both cases male phenotypes were reported for Rio de Janeiro, where K. ocellatus (males and hermaphrodites, previously known as K. caudomarginatus Seegers) occurs in syntopy with $K$. hermaphroditus making these records more doubtful. The potential records described above, the presence of males on populations of $K$. marmoratus (Avise $\&$ Tatarenkov, 2015), as well as the cryptic and complex mangrove microhabitats inhabited by $K$. hermaphroditus, may have led Costa (2006) and Lira et al. (2015) to not fully discard the presence of males of $K$. hermaphroditus, despite extensive sampling and no reliable scientific evidence of males have been made available up to that moment.

The recently collected specimen of Kryptolebias hermaphroditus with male appearance, described herein, matches the description of the putative $K$. hermaphroditus males mentioned by Costa (2006) and K. marmoratus males (Davis et al., 1990; Soto \& Noakes, 1994; Costa, 2011). Although gonadal histological evidence was not surveyed in order to maintain the unique specimen integrity, its morphological characters support this first documentation of a male $K$. hermaphroditus. This evidence includes orange body and fins, faded ocellus, black margins of anal and caudal fins and cylindrical urogenital papillae (Costa, 2011). Once the color pattern of males is the most conspicuous character for differentiating cynolebiid species (Costa, 2003), the discovery of a $K$. hermaphroditus male may reveal important morphological differences between this species and $K$. marmoratus.

Regardless the presence of an ocellus on the caudal peduncle, it appeared faded in comparison to that of hermaphrodite individuals. According to Soto \& Noakes (1994), the most distinctive characters attributed to Kryptolebias marmoratus males are: a bright orange overall coloration and the absence of a distinct caudal ocellus. However, they also considered that individuals with intermediate phenotypes (with orange color and a faded ocellus) could also be males. Davis et al. (1990) had previously mentioned that it is not possible yet to distinguish primary and secondary males, the latter of which result from sex change of functional hermaphrodites into males due to environmental conditions (Harrington, 1971). Huber (1992) cited the presence of ocellus in secondary males of $K$. ocellatus, which agrees with our specimen description. However, as discussed above, this report was not afterwards confirmed.

Primary males of Kryptolebias marmoratus can be readily produced in laboratories by inducing eggs to temperatures lower than those usually found in mangrove 
areas $\left(<20^{\circ} \mathrm{C}\right)$, while secondary males can be induced by maintaining individuals at higher temperatures $\left(>30^{\circ} \mathrm{C}\right)$, which are similar to those found on populations with higher rate of males (Turner et al., 2006; Earley et al., 2012). Their induction in the lab at naturally occurring temperatures suggests that, in the wild, secondary males may be the most ecologically relevant type of male (Turner et al., 2006). This may also be the case for $K$. hermaphroditus in northeastern Brazil, where higher temperatures are predominant due to the Equator's line proximity.

Davis et al. (1990) demonstrated distinct male phenotypes within Kryptolebias marmoratus. One, from Twin Cays, Belize, exhibited a dark orange color pattern, an inconspicuous caudal ocellus, and caudal black margins along the dorsal, anal and caudal fins. The other one, from Florida, USA, exhibited a bright orange coloration almost devoid of dark chromatophores, except the head. Ellison et al. (2012) also found a male of K. marmoratus with orange coloration, faded ocellus and black borders on the anal and caudal fins in Belize; a pattern similar to that of the $K$. hermaphroditus male herein described.

Between 2011 and 2015, during extensive surveys at the Ceará-Mirim River estuary (Lira et al., 2015), we collected 107 hermaphrodites before finding this single male. This apparent rarity of males aligns with the extremely low degree of heterozygosis reported for populations of Kryptolebias hermaphroditus from southeastern Brazil (Tartarenkov et al., 2011). Together with absence of male specimens in all known populations (Costa, 2011; Lira et al., 2015), these findings suggest that self-fertilizing hermaphroditism is the major mode of reproduction in $K$. hermaphroditus. However, the persistent occurrence of male individuals in $K$. marmoratus, but at low densities (varying from $1 \%$ in Florida to $10-25 \%$ in Belize, Davis et al., 1990), suggests that sexual outcrossing serves an adaptive role within natural populations, possibly contributing to genetic diversity that helps the species to deal with new environmental pressures, such as parasites loads (Ellison et al., 2011, 2013).

The occurrence of self-fertilization in Kryptolebias marmoratus has made that species a popular model for population genetics, development, evolutionary biology, behavior, among others (for reviews see Earley et al., 2012; Taylor, 2012; Avise \& Tatarenkov, 2015; Turko \& Wright, 2015). Nonetheless, there have been relatively few studies on the South American lineage of $K$. hermaphroditus, possibly due to its misidentification as $K$. marmoratus (Seegers, 1984). Additionally, the difficulties of working in mangrove environments, which represent a complex, multi-dimensional, and cryptic habitat with variable environmental and physical features could also contributed to the scarcity of studies on the South American lineage (Taylor, 2012).

The discovery of a male specimen encourages more studies on Kryptolebias hermaphroditus. While researchers have addressed some aspects of systematics
(Costa, 2006, 2011), evolutionary history (Costa et al., 2010; Tatarenkov et al., 2009, 2011), and geographic distribution (Sarmento-Soares et al., 2014; Lira et al., 2015), there is little available information regarding natural history, ecology and population dynamics. Despite the large gap in our knowledge of the biology of $K$. hermaphroditus, the recent studies above mentioned, including the present one, suggest some interesting perspectives for studies on evolution, morphology, behavior and physiology across the species' wide geographic distribution in the mangroves of the Brazilian coast.

\section{Acknowledgements}

We thank Lucas Medeiros, Mateus Lira and Roney Paiva for helping with fieldwork, and to Luciano BarrosNeto for providing the pictures of the live specimens. Carlos Eduardo Alencar provided information about mangrove crabs in the Ceará-Mirim estuary. Graco Viana and Centro de Treinamento em Aquicultura da Universidade Federal do Rio Grande do Norte provided logistical support. Waldir Berbel-Filho receives a $\mathrm{PhD}$ scholarship from Science without Borders Program/CNPq (process \#233161/2014-7) and Helder Espírito-Santo received a Postdoctoral fellowship from PDJ Program/ CNPq (process \#168228/2014-9).

\section{References}

Avise, J. C. \& A. Tatarenkov. 2015. Population genetics and evolution of the mangrove rivulus Kryptolebias marmoratus, the world's only self-fertilizing hermaphroditic vertebrate. Journal of Fish Biology, 87: 519-538.

Costa, W. J. E. M. 1995. Pearl killifishes: the Cynolebiatinae: systematics and biogeography of the Neotropical annual fish subfamily. Neptune city, TFH Publications, $128 \mathrm{p}$.

Costa, W. J. E. M. 2003. Family Rivulidae. Pp. 526-548. In: Reis, R. E., S. O. Kullander \& C. J. Ferraris Jr. (Eds.). Check list of freshwater fishes of South and Central America. Porto Alegre, Edipucrs.

Costa, W. J. E. M. 2006. Redescription of Kryptolebias ocellatus (Hensel) and K. caudomarginatus (Seegers) (Teleostei: Cyprinodontiformes: Rivulidae), two killifishes from mangroves of south-eastern Brazil. Aqua Journal of Ichthyology and Aquatic Biology, 11: 5-12.

Costa, W. J. E. M. 2009. Peixes aploqueilóideos da Mata Atlântica brasileira: história, diversidade e conservação. Rio de Janeiro, Museu Nacional. 171p.

Costa, W. J. E. M. 2011. Identity of Rivulus ocellatus and a new name for a hermaphroditic species of Kryptolebias from southeastern Brazil (Cyprinodontiformes: Rivulidae). Ichthyological Exploration of Freshwaters, 22: 185-192.

Costa, W. J. E. M., S. M. Q. Lima \& R. Bartolette. 2010. Androdioecy in Kryptolebias and the evolution of selffertilizing hermaphroditism. Biological Journal of the Linnean Society, 99: 344-349. 
Davis, W. P., D. S. Taylor \& B. J. Turner. 1990. Field observations of the ecology and habits of mangrove rivulus (Rivulus marmoratus) in Belize and Florida (Teleostei: Cyprinodontiformes: Rivulidae). Ichthyological Exploration of Freshwaters, 1: 123-134.

Earley, R. L., A. F. Hannineb, A. Fuller, M. J. Garcia \& E. A. Lee. 2012. Phenotypic plasticity and integration in the mangrove rivulus (Kryptolebias marmoratus): a prospectus. Integrative and Comparative Biology, 52: 814-827.

Ellison, A., J. Cable \& S. Consuegra. 2011. Best of both worlds? Association between outcrossing and parasite loads in a selfing fish. Evolution, 65: 3021-3026.

Ellison, A., P. Wright, D. S. Taylor, C. Cooper, K. Regan, S. Currie \& S. Consuegra. 2012. Environmental diel variation, parasite loads, and local population structuring of a mixedmating mangrove fish. Ecology and Evolution, 2: 1682-1695.

Ellison, A., J. Jones, C. Inchley \& S. Consuegra. 2013. Choosy males could help explain androdioecy in a selfing fish. The American Naturalist, 181: 855-862.

Harrington, R. W. 1971. How ecological and genetic factors interact to determine when self-fertilizing hermaphrodites of Rivulus marmoratus change into functional secondary males, with a reappraisal of the mode of intersexuality among fishes. Copeia, 1971: 389-432.

Huber, J. H. 1992. Review of Rivulus: ecobiogeographyrelationships. Paris, Cybium, Société Française d'Ichtyologie, $572 \mathrm{p}$.

Lira, M. G. S., R. E. C. Paiva, T. P. A. Ramos \& S. M. Q. Lima. 2015. First record of Kryptolebias hermaphroditus Costa, 2011 (Cyprinodontiformes: Rivulidae) in the extreme north Atlantic Forest mangroves, Rio Grande do Norte state, Brazil. Check List, 11: 1656.

Sarmento-Soares, L. M., L. F. S. Ingenito, L. F. Duboc, R. F. Martins-Pinheiro, R. Borçato \& J. P. Silva. 2014. Primeiros registros de Kryptolebias ocellatus (Hensel) (Cyprinodontiformes, Rivulidae) para riachos de Mata Atlântica no Espírito Santo. Boletim da Sociedade Brasileira de Ictiologia, 111: 15-19.
Soto, C. G. \& D. L. G. Noakes. 1994. Coloration and gender in the hermaphroditic fish Rivulus marmoratus Poey (Teleostei: Rivulidae). Ichthyological Exploration of Freshwaters, 5: 79-90.

Tatarenkov, A., S. M. Q. Lima, D. S. Taylor \& J. C. Avise. 2009. Long-term retention of self-fertilization in a fish clade. Proceedings of the National Academy of Sciences, 106: 14456-14459.

Tatarenkov, A., S. M. Q. Lima \& J. C. Avise. 2011. Extreme homogeneity and low genetic diversity in Kryptolebias ocellatus from south-eastern Brazil suggest a recent foundation for this androdioecious fish population. Journal of Fish Biology, 79: 2095-2105.

Taylor, D. S. 2012. Twenty-four years in the mud: What have we learned about the natural history and ecology of the mangrove rivulus, Kryptolebias marmoratus? Integrative and Comparative Biology, 52: 724-736.

Turko, A. J. \& P. A. Wright. 2015. Evolution, ecology and physiology of amphibious killifishes (Cyprinodontiformes). Journal of Fish Biology, 87: 815-835.

Turner, B. J., M. T. Fisher, D. S. Taylor, W. P. Davis \& B. L. Jarrett. 2006. Evolution of 'maleness' and outcrossing in a population of the self-fertilizing killifish, Kryptolebias marmoratus. Evolutionary Ecology Research, 8: 1475-1486.
Submitted March 6, 2016 Accepted August 18, 2016 by Paulo Lucinda 